\title{
EM BUSCA DE SI: CONSTRUÇÃO IDENTITÁRIA NO POEMA MARABÁ, DE GONÇALVES DIAS
}

\author{
SILVA, Josimere Maria da ${ }^{1}$ \\ SILVA, Hudson Marques da ${ }^{2}$
}

RESUMO: Este trabalho consiste em promover uma leitura hermenêutico-discursiva do poema "Marabá", do escritor romântico brasileiro Gonçalves Dias. Nesse poema, o eu lírico (a índia Marabá) vivencia um conflito em sua comunidade ao ser rejeitada por seus pares em função de sua origem miscigenada: ela é filha de indígena com europeu. A fim de compreender esse descompasso identitário no poema, esta leitura mobiliza alguns conceitos tais como heterogeneidade discursiva (BRANDÃO, 2004), fronteira (AUGÉ, 2010), sujeito (TOURAINE, 2004), identidade (HALL, 2006), cuidado de si (FOUCALT, 2006) e cidadania (MANZINI-COVRE, 2007). Busca-se então pormenorizar a angústia de uma persona que foi destituída de sua condição de ser-no-mundo, na medida em que não é reconhecida pela imagem que construiu de si e para si. Pontua-se, portanto, como esses elementos heterogeneidade discursiva, fronteira, sujeito, identidade e cidadania - colaboram para a construção identitária de Marabá.

PALAVRAS-CHAVE: Linguagem, Sujeito Discursivo, Identidade, Cidadania.

\section{PURSUING HERSELF: IDENTITY CONSTRUCTION IN THE POEM MARABÁ, BY GONÇALVES DIAS}

\begin{abstract}
This paper aims to analyze the poem "Marabá", by the Brazilian romantic writer Gonçalves Dias. In this poem, the persona (the native Marabá) experiences a conflict in her community for being rejected by her peers because of her mixed origin: daughter of native indian mother and
\end{abstract}

\footnotetext{
${ }^{1}$ Doutora em Literatura e Interculturalidade pela Universidade Estadual da Paraíba. Professora do Instituto Federal de Educação, Ciência e Tecnologia de Alagoas. E-mail: josimaria.ll@gmail.com

${ }^{2}$ Doutor em Literatura e Interculturalidade pela Universidade Estadual da Paraíba. Professor do Instituto Federal de Educação, Ciência e Tecnologia de Pernambuco. E-mail: marqueshudson@ @otmail.com
} 


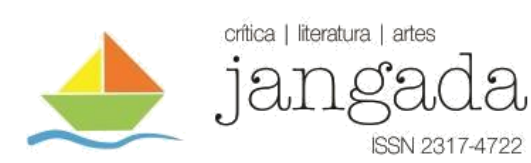

European father. In order to understand this identity mismatch in the poem, this analysis approaches some concepts such as discursive heterogeneity (BRANDÃO, 2004), frontier (AUGÉ, 2010), subject (TOURAINE, 2004), identity (HALL, 2006), care of the self (FOUCALT, 2006) and citizenship (MANZINI-COVRE, 2007). Hence, it aims to detail the anguish of a persona who has been dismissed from her condition of being-in-the-world, since she is not recognized for her self-image. Therefore, it points out how such elements - discursive heterogeneity, frontier, subject, identity and citizenship - can influence Marabá's identity construction.

KEYWORDS: Language; Discursive Subject; Identity. Citizenship.

\section{INTRODUÇÃO}

O que se denominou como Romantismo literário brasileiro começou a ganhar feições na primeira metade do século XIX. Alguns de seus mais reconhecidos escritores se propuseram a uma tarefa um tanto forjada e, sobremaneira, estereotipada: promover uma identidade nacional. Ainda mais forjada se torna esta tarefa se considerado que, entrando no terceiro século de imposição cultural europeia, o Brasil ainda vivia, neste momento, sob os parâmetros do Velho Continente, o que significa que o âmbito das artes, dentre outros, caracterizava-se como importações dos moldes europeus. Mas como essa nova estética literária tinha, entre outros aspectos, a tarefa de abordar em suas obras elementos representativos do que poderia ser a nação brasileira, incluindo seu povo nativo, sua paisagem, suas práticas culturais etc., a grande questão seria: como desenhar uma identidade de um povo de origens multifacetadas? Como estabelecer uma identidade para um povo que surgiu de um mix triádico entre nativos indígenas, brancos europeus e negros africanos?

Em um momento em que, há poucas décadas, na Europa, se dera o nascimento do cidadão, os escritores românticos tinham, aqui no Brasil, a incumbência de transformar o indivíduo até então suprimido e ignorado por todo o processo de colonização em personagem principal de suas obras. E eis que a figura do indígena emerge como protagonista na primeira fase do Romantismo brasileiro, especialmente na escrita de Gonçalves Dias, um dos nomes mais representativos dessa estética literária que se convencionou chamar de indianismo.

A independência de 1822 trouxe consigo a urgência de uma definição de nação brasileira, o que justifica o comprometimento dos românticos com o projeto nacional. Diante da ideia de nação, especialmente no século XIX, vê-se a necessidade da existência de uma 


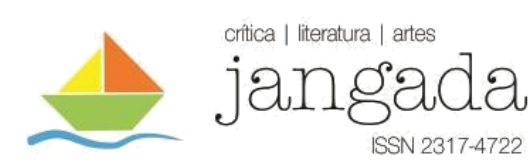

identidade para o povo brasileiro, para quem a ideia de identidade estaria convergindo com o desejo de liberdade. Era preciso dar um basta na dominação do colonizador e passar a valorizar os diversos aspectos do nosso território, a começar pela natureza e pelo nativo, partir das peculiaridades para se chegar à consolidação de uma nação brasileira.

O poeta Gonçalves Dias, embora tenha se destacado pela abordagem dos “[ [... grandes temas românticos do amor, da natureza e de Deus" (BOSI, 2006, p. 110), há de ser lembrado também por sua veia indianista, vertente em que articulou "[...] o ponto exato em que o mito do bom selvagem [...] acabou por fazer-se verdade artística" (BOSI, 2006, p. 110). Entre suas diversas produções, nas quais a figura do indígena aparece em primeiro plano, encontra-se "Marabá", um poema que apresenta a imagem desconcertada de uma mulher, filha de uma indígena com um branco europeu, e que recebe o mesmo nome do poema. Marabá poderia ser a representação mais autêntica do povo brasileiro por ser o resultado da mistura, dessa miscigenação, já que assim se constituiu o povo brasileiro. No entanto, é exatamente o fato de ela ser fruto de uma mistura, inconcebível, ressalte-se, que dá corpo ao poema gonçalvino. Por não ser "pura", Marabá não pertence nem aos indígenas nem aos europeus. Ela situa-se num entrelugar que a incomoda e que lhe dá uma voz angustiada. Desse espaço é que emergirá um sujeito discursivo que expõe através de sua fala toda a angústia de um não-ser. É, pois, essa expressão angustiada que interessa aqui, porque é através dela que o eu lírico se revela em toda sua complexidade, evidenciando problemáticas relacionadas às noções de cidadania (ou da ausência dela), de sujeito, de identidade. Esse será, portanto, o percurso deste ensaio: identificar nesse sujeito discursivo compreendido na fala de Marabá elementos que justifiquem sua postura de um ser deslocado e desolado, à procura de uma identidade que lhe garanta a aceitação perante o outro.

\section{PRESSUPOSTOS TEÓRICOS: SUJEITO DISCURSIVO E CONSTRUÇÃO IDENTITÁRIA}

Numa discussão que elenca algumas abordagens sobre a noção de sujeito discursivo, Brandão (2004, p. 59) defende a existência de um sujeito "essencialmente histórico" e, por isso mesmo, também ideológico, que apresenta em sua fala "um recorte das representações de um tempo histórico e de um espaço social". Desse espaço é que o sujeito, numa relação natural com o outro, emite o seu discurso. Este, por seu turno, não surge instantaneamente sem origem ou destino. $\mathrm{O}$ fato de que o sujeito que o materializa encontra-se historicamente situado determina Jangada | nr. 16, jun/dez, 2020 | ISSN 2317-4722 


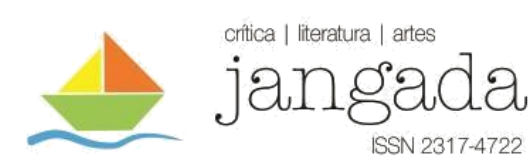

que o discurso parte de um planejamento prévio e tem, sempre, um destinatário previsto. Sendo assim, a teórica defende que não há um sujeito único, no sentido benvenisteano, que apresente um discurso puro, original ou neutro, mas um sujeito que aglutina discursos e, inevitavelmente, acumula outros discursos em seu discurso. Dessa forma, a pensadora conclui que "[...] a noção de subjetividade não está mais centrada na transcendência do $E G O$, mas relativizada no par $E U$ $T U$ " (BRANDÃO, 2004, p. 59).

Nessa discussão, Brandão mobiliza uma concepção heterogênea de linguagem, segundo a qual o sujeito "[...] divide o espaço discursivo com outro" (BRANDÃO, 2004, p. 60). E aqui interessa essa premissa para poder se pensar no "outro" que divide espaço com Marabá. Posteriormente, busca-se identificar: que outros participam de seu discurso? Que outros contribuem para sua construção? Que outros seriam seus interlocutores? Que elementos históricos estariam intrincados em sua fala inquieta?

Entre os exemplos de formas de heterogeneidade discursiva que Brandão aponta a partir de Authier-Revuz, interessa aqui destacar: a) o discurso relatado indireto - em que o locutor "[...] usa de suas próprias palavras para remeter a uma outra fonte de "sentido" -, ao lado do discurso relatado direto - em que o locutor "[...] recorta as palavras do outro e cita-as" - e b) as formas marcadas de conotação autonímica - em que

[...] o locutor inscreve no seu discurso, sem que haja interrupção do fio discursivo, as palavras do outro, mostrando-as, assinalando-as quer através de aspas, do itálico, de uma entonação específica, quer através de um comentário, uma glosa, um ajustamento, ou de uma remissão a um outro discurso, funcionando como 'marcas de uma atividade de controle/regulagem do processo de comunicação. (BRANDÃO, 2004, p. 60)

Especialmente este último exemplo fornece respaldo para identificar a heterogeneidade que há na fala do eu lírico presente no poema Marabá. Um eu que sai de si ao mesmo tempo em que arrasta o outro para dentro de si através de sua fala. Um eu que se apodera do discurso do outro para expressar sua forma de ver a si mesmo.

Na verdade, tanto Brandão quanto Authier-Revuz estão tratando da já conhecida teoria polifônica de Bakhtin, segundo a qual “[...] a verdadeira substância da língua [...] não é constituída por um sistema abstrato de formas linguísticas [...] mas pelo fenômeno social da interação verbal, realizada através da enunciação e das enunciações" (BAKHTIN apud Jangada | nr. 16, jun/dez, 2020 | ISSN 2317-4722 
BRANDÃO, 2004, p. 61). É dessa interação, pois, que se pode compreender a existência quase inevitável de um outro no discurso. É do outro que o sujeito se constitui através de "máscaras" representativas das várias vozes que entremeiam o seu discurso.

Compreende-se, assim, que somente tomando Marabá enquanto um sujeito discursivo é que se podem capturar outras implicações constitutivas de sua identidade. Mas um sujeito discursivo polifônico, situado num cenário sócio-histórico-ideológico que o leva a assumir posturas e visões permeadas pelas influências não só do espaço onde vive, mas de todos que o compõem.

Considere-se, então, o espaço em que se situa Marabá e tome-se agora um outro rumo: a noção de fronteira. Segundo Augé (2010, p. 19-20), trata-se de uma noção que, “[...] desde a aparição da linguagem, se seguirmos Lévi-Strauss, é empregada para significar o universo, para dar sentido ao mundo [...]", mas que, na verdade, se transfigura em uma atividade que "[...] consistiu em opor categorias [...] para simbolizar o espaço, compartimentando-o", algo que atualmente não se coloca como necessário, já que não há na ciência atual espaço para “oposições binárias", embora existam as desigualdades próprias da globalização e que erguem muros/fronteiras dos mais diversos.

O teórico ressalta que “[...] a força dos enclausuramentos comunitários, nacionais, étnicos ou outros" e a necessidade de que estes não sejam ignorados frente a um mundo "sobremoderno", mas que se configura num lugar onde "[...] afrontam-se as diferenças e as desigualdades" (AUGÉ, 2010, p. 22-23), porque nessa realidade composta por fragmentos opostos estaria o terreno mais propício para a construção de fronteiras não somente naturais, mas também linguísticas, culturais e políticas. A estas, para elucidar o caso Marabá, acrescentase a fronteira étnica, por motivos que serão explicitados nesta análise. De antemão, identificase nela um sujeito que viu erguerem-se ao seu redor diversas fronteiras invisíveis, mas tão firmes quanto muros ou montanhas de concreto.

Touraine (2004) aponta para a necessidade de o indivíduo se tornar sujeito para conquistar sua liberdade. Para isso, segundo ele, é preciso romper com a proposta que aponta para dois lados opostos e segmentados e que "[...] nega a existência do social, dos níveis intermediários" (TOURAINE, 2004, p. 95). Estaria na desordem, no caos, o ponto de partida para essa busca da subjetividade: “A partir do momento em que sofre com a fragmentação, você procura tornar-se um sujeito através do indivíduo ou do grupo" (TOURAINE, 2004, p. 96). Ora, sujeito fragmentado significa sujeito instável. E essa instabilidade do sujeito, para Touraine, converge para a ideia de "desaparecimento progressivo das normas de estabilidade" 
(TOURAINE, 2004, p. 96), normalmente impostas pelas instâncias de poder, no sentido foucaultiano.

A defesa de Touraine é de que "o sujeito não é um indivíduo concreto", ele se constitui na medida em que se coloca "em face de si". O autor defende a necessidade de um afastamento de si para que o sujeito possa definir sua relação consigo. Assim, o sujeito apenas teria consciência de si estando fora de si. Em outros termos, a subjetivação só é possível após a dessubjetivação - uma espécie de "destruição de si”, inevitável "[...] quando a combinação, a síntese e a integração se tornam inoperantes” (TOURAINE, 2004, p. 97-99). É nesse cenário de inoperância que se situa o eu lírico de Marabá. Talvez desse lugar se possa perceber a existência de um espaço em que ela própria seja a síntese, mas a síntese rejeitada, porque resultado da mistura mais improvável, da junção de dois polos: o nativo e o europeu, o dominado e o dominador.

Que identidade, então, pode ter ou mesmo criar para si um sujeito situado no caos? Certamente não se aplica aí a identidade do sujeito iluminista, para Hall (2006, p. 11), "[...] uma concepção muito 'individualista' do sujeito e de sua identidade”. O autor nos aponta ainda outras duas concepções de identidade: a do sujeito sociológico e a do sujeito pós-moderno. No primeiro caso, vê-se a figura de um sujeito que se constrói na interação com a sociedade. Nesse caso, o sujeito "[...] é formado e modificado num diálogo contínuo com os mundos culturais 'exteriores' e as identidades que esses mundos oferecem", enquanto a identidade “[...] preenche o espaço entre o 'interior' e o 'exterior' - entre o mundo pessoal e o mundo público" (HALL, 2006, p. 11). É interessante notar que, segundo Hall, na medida em que o sujeito se projeta nessas "identidades culturais", também ele absorve seus valores, o que acaba por estabelecer o seu lugar no mundo. Para o teórico, "A identidade, então, costura [...] o sujeito à estrutura" (HALL, 2006, p. 12), concorrendo para um processo de unificação em que ambos se tornam desprezíveis, dada a incompletude de ambos sem a intersecção. Mas esse sujeito está passando por um processo de fragmentação que lhe dá várias identidades, evidenciando o sujeito pósmoderno. Nesse segundo caso, encontra-se um sujeito diverso, possuidor de identidades mutáveis e contraditórias e no qual uma ideia de identidade "[...] plenamente unificada, completa, segura e coerente é uma fantasia" (HALL, 2006, p. 13).

Esse sujeito fragmentado, pois, encontra-se também deslocado. E a questão passa a ser a busca de uma identidade nesse terreno movediço que é a modernidade. Marabá parece procurar uma identidade no caos em que se encontra. Ela se apresenta em meio a uma estrutura que a faz sentir a necessidade de encontrar a si. Entra em cena a noção do "cuidado de si" 


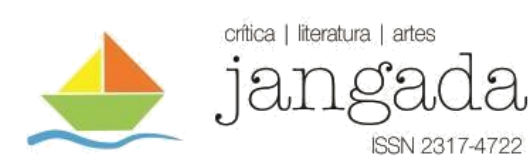

apontada por Foucault (2006, p. 14) como "Certa forma de atenção, de olhar. Converter o olhar, do exterior para si". Nesse caso, o sujeito do "cuidado de si" tem a tarefa de voltar-se para si para identificar-se a si. É o sujeito que se importa consigo e que, ao olhar para seu interior, caminha para a construção de sua subjetividade.

Mansini-Covre (2007), ao discutir a noção de cidadania, defende que "Só existe cidadania se houver a prática da reivindicação, da apropriação de espaços, da pugna para fazer valer os direitos de cidadão" (MANSINI-COVRE, 2007, p. 10), e aí estariam implícitos, também, os deveres. De qualquer forma, compreende-se que a questão da cidadania implica uma atitude do indivíduo em busca do seu lugar de sujeito, uma atitude configurada na ocupação desses espaços que lhe pertencem e que estariam à sua espera e disposição. Ao perceber-se rejeitada por todos, Marabá inicia uma busca pela sua identidade perdida. Ela, resultado da mistura, e, por isso, destituída de uma identidade própria, parece ter sido destituída também de sua condição de cidadã, na medida em que, pelo mesmo motivo, também não é reconhecida como sujeito.

\section{MARABÁ E OS DISCURSOS IDENTITÁRIOS EM CONFLITO}

"Marabá" é mais um poema gonçalvino que, como tantos outros, apresenta um ritmo marcado numa sinfonia que quase sempre busca explorar o som que faz parte da vida dos indígenas. Bosi (2006, p. 114) ratifica que "[...] a sinfonia dos seus hendecassílabos [...] orquestram o clímax da procela através de um riquíssimo jogo de timbres”. Especialmente em Marabá, verifica-se um eu lírico angustiado que se vê a partir do outro e que exprime sua angústia a partir do discurso do outro. Numa mesclagem de redondilhas menores e hendecassíbalos, o eu lírico se apresenta como um indivíduo guiado por sentimentos diversos, mas aparentemente originados de um específico, a rejeição:

Eu vivo sozinha; ninguém me procura!

Acaso feitura

Não sou de Tupá?

Se algum dentre os homens de mim não se esconde,

— Tu és, me responde,

— Tu és Marabá! 


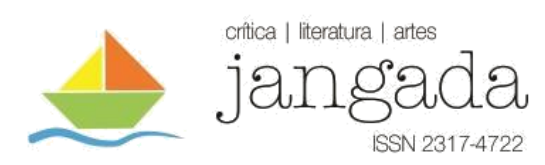

Já nos primeiros versos, nota-se um eu lírico solitário, que não é aceito pelo outro e que, por isso, começa a questionar tal rejeição. Não seria a jovem Marabá filha do mesmo deus para ser tão rejeitada? Mas é o discurso do outro que lhe dá a primeira e inquestionável resposta: “...és Marabá"; ou seja: és mistura.

Considerando o sentido da palavra enquanto síntese da mistura do branco com o índio, então se identifica uma primeira evidência: Marabá é rejeitada porque é fruto da miscigenação; logo, ela estaria tomando por interlocutor ou o branco ou o indígena, ou ambos. E assim a resposta que recebe quando pergunta se não seria filha de Tupã certamente viria de um desses dois, curiosamente, os dois que se fazem nela e que automaticamente participam de seu discurso. A heterogeneidade discursiva apontada por Brandão (2004) materializa-se no poema Marabá na medida em que a fala do eu lírico é reiterada pelos seus interlocutores. Ela se apropria do discurso dos outros porque está tomada por eles, porque se constitui neles, de forma que, mesmo com o uso de aspas e travessões, não é tão óbvio distinguir quando/quem está falando no poema, o que confirma a presença da conotação autonímica, defendida por Brandão (2004), e que permite a Marabá emitir um discurso pautado nas “palavras do outro".

Mas o que é possível perceber no decorrer do poema é que Marabá está cercada por uma fronteira que não é física, porém intransponível, no sentido de que não pode ser vencida uma fronteira étnico-racial - e que a enclausura em si mesma, já que não seria puramente indígena nem puramente europeia. Na verdade, através do poema, Gonçalves Dias denuncia o eurocentrismo, que não aceitava a miscigenação, mesmo que ela fosse uma realidade de todos os povos, inclusive na Europa. Mas não se reduz a isso, no poema, o indígena também toma a mesma posição de negação da mistura. Portanto, a atitude de rejeição chega a Marabá de forma unânime, ninguém a aceita como é e esta é a grande fronteira: a origem étnica da jovem se transpõe em seu redor e aí se afrontam as diferenças que a isolam daqueles com quem ela deveria se relacionar.

Mas Marabá não se conforma e continua sua busca inquietante, argumentando:

— Meus olhos são garços, são cor das safiras,

— Têm luz das estrelas, têm meigo brilhar;

- Imitam as nuvens de um céu anilado,

- As cores imitam das vagas do mar! 
É interessante notar a recorrência de metáforas através das quais Marabá se caracteriza. Ela se assemelha à natureza através de substantivos que nomeiam elementos naturais e que estão presentes no cenário brasileiro: safiras, estrelas, nuvens, mar. Diante da evidência do sentimento de desprezo por parte do outro, a jovem se apresenta como sendo dotada de características inquestionáveis, o que reforça a postura nacionalista de Gonçalves Dias e que, no poema, seria o argumento mais plausível para Marabá convencer sua comunidade a aceitála. Assim, Marabá se vê, mas não é assim que ela é vista, mesmo que tenha olhos de safira, como é possível observar na estrofe seguinte:

Se algum dos guerreiros não foge a meus passos:

"Teus olhos são garços,

Responde anojado; "mas és Marabá:

"Quero antes uns olhos bem pretos, luzentes,

"Uns olhos fulgentes,

"Bem pretos, retintos, não cor d'anajá!"

Notam-se nas duas estrofes anteriores dois olhares definidores de Marabá: o primeiro é o dela própria: "Meus olhos são garços, são cor das safiras"; o segundo é o do outro: "Teus olhos são garços, /Responde anojado; mas és Marabá". O que se percebe é que o entrecruzamento desses dois olhares gera uma certa desestabilização confirmada no verso seguinte: "Quero antes uns olhos bem pretos, luzentes". A confirmação da rejeição gera o caos que abala a subjetividade de Marabá, na perspectiva de Touraine. É a partir daí que a jovem começa de forma desenfreada uma busca por sua identidade. Se o sujeito "[...] se constitui na medida em que se coloca em face de si" (TOURAINE, 2004 p. 96), parece ser esta a atitude de Marabá. Ela parece colocar-se em face de si para mostrar ao outro um sujeito que este não reconhece nela, como mostram as estrofes 4,6 e 8 :

- É alvo meu rosto da alvura dos lírios,

- Da cor das areias batidas do mar;

- As aves mais brancas, as conchas mais puras

- Não têm mais alvura, não tem mais brilhar. -

- Meu colo de leve se encurva engraçado,

- Como hástea pendente do cactos em flor; 
- Mimosa, idolente, resvalo no prado,

- Como um soluçado suspiro de amor! -

- Meus loiros cabelos em ondas se anelam,

- O oiro mais puro não tem seu fulgor;

- As brisas nos bosques de os ver se enamoram.

- De os ver tão formosos como um beija-flor!

A jovem elenca elementos que, para ela, seriam positivos no sentido de proporcionar sua aceitação perante seu interlocutor. No entanto, as estrofes 5, 7 e 9, alternadas às anteriores como forma de respostas, continuam desconstruindo seus argumentos:

Se ainda me escuta meus agros delírios:

- "És alva de lírios,"

Sorrindo responde; "mas és Marabá:

"Quero antes um rosto de jambo corado.

" $U m$ rosto crestado

"Do sol do deserto, não flor de cajá."

"Eu amo a estatura flexível, ligeira,

Qual duma palmeira,"

Então me respondem; “tu és Marabá:

"Quero antes o colo da ema orgulhosa,

"Que pisa vaidosa,

"Que flóreas campinas governa, onde está."

Mas eles respondem: "Teus longos cabelos,

"São loiros, são belos,

"Mas são anelados; tu és Marabá:

"Quero antes cabelos, bem lisos, corridos,

"Cabelos compridos,

"Não cor de oiro fino, nem cor de anajá."

Ao que parece, nem o tom confessional de Marabá é capaz de proporcionar a aceitação que ela busca. Cada argumento seu é rebatido. Os cabelos são loiros, mas são anelados; ela é 


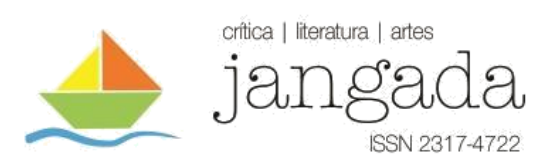

alva, mas é Marabá. Atente-se para o paralelismo adversativo presente no discurso do interlocutor de Marabá como um reforço aos seus argumentos que insistem em apontar as características tidas como negativas da jovem e que o fazem renegá-la, situando-a num caos interior.

Aqui se pode retomar um tema apontado anteriormente: que identidade pode ter um sujeito situado no caos? Retomando Hall, do caos certamente não surgirá um sujeito iluminista, mas um sujeito plural, que talvez abarque as duas concepções de identidade indicadas pelo autor: a identidade de sujeito sociológico, no sentido de que se constrói na interação com a sociedade, e a identidade de um sujeito pós-moderno, fragmentado e deslocado, visto que procura sua identificação em um terreno movediço. Marabá, na procura por sua identidade, revela-se um sujeito mutável, multifacetado. Ela é o que vê em si, mas também aquilo que o outro percebe nela. Na mistura de concepções que convergem para sua identificação como sujeito é que ela vai absorvendo uma possível modelagem mosaica. Se, para Hall (2006, p. 12), "A identidade, então, costura [...] o sujeito à estrutura", reitera-se a ideia de incompletude, caso não haja uma intersecção entre ambos. Assim, a identidade surge da interação do sujeito com o espaço em que ele se insere.

A necessidade de ser aceito pelo outro situa Marabá em uma jornada em busca de si. Nesse processo, ela procura apontar seus aspectos positivos numa tentativa de agradar a esse outro. O uso de tantos adjetivos reforça essa ideia. Ao longo de todo o poema, o eu lírico evidencia a necessidade de ser aceito pelo outro. Marabá inicia uma busca pelo seu interior à procura de algo que desperte em seu interlocutor certo interesse. Portanto, ela revela um sujeito do "cuidado de si", tratado por Foucault como aquele que, na tarefa de se importar consigo, naturalmente volta seu olhar para si, o que o encaminha para a construção de sua subjetividade.

No caso de Marabá, porém, sua aceitação de si mesma parece estar condicionada a sua aceitação pelo outro, o que não ocorre, o que potencializa essa rejeição, pois é o fato de ela não ser aceita por ser o que é: uma mulher que apresenta traços físicos tanto dos indígenas quanto do branco europeu. Situada num entrelugar sem precedentes, a mestiça é rejeitada por ambos e se aflige. Ela não pertence nem a uma etnia, nem à outra; é destituída de seu lugar de sujeito, o que promove uma reflexão sobre a sua condição de cidadã. Para isso, verificam-se as duas últimas estrofes do poema:

E as doces palavras que eu tinha cá dentro

A quem nas direi? 
$O$ ramo de acácia na fronte de um homem

Jamais cingirei:

Jamais um guerreiro da minha arazóia

Me desprenderá:

Eu vivo sozinha, chorando mesquinha,

Que sou Marabá!

Como apontado anteriormente, a partir de Mansini-Covre (2007, p. 10), "Só existe cidadania se houver a prática da reivindicação, da apropriação de espaços, da pugna para fazer valer os direitos de cidadão". E aqui se identifica um paradoxo: no decorrer de todo o poema, com exceção das duas últimas estrofes, encontra-se um indivíduo buscando seu lugar, reivindicando, argumentando. Nesse caso, nota-se em Marabá uma cidadã, segundo MansiniCovre, na medida em que ela estaria lutando por sua aceitação, pelo seu espaço. No entanto, as duas últimas estrofes apresentam um ser vencido: "Jamais um guerreiro da minha arazóia/ Me desprenderá: /Eu vivo sozinha, chorando mesquinha, /Que sou Marabá!”.

Após internalizar toda a rejeição que sofreu, Marabá lhe dá a sentença final: "sou Marabá”. Ela parece ter aceitado a condição que lhe foi imposta por seu interlocutor e, mesmo sofrendo, como se observa em "E as doces palavras que eu tinha cá dentro/A quem nas direi?", começa a proferir o mesmo discurso contra o qual argumentava anteriormente. Ora, se se defendeu anteriormente que a questão da cidadania implica uma atitude do indivíduo em busca do seu lugar de sujeito, conclui-se que, ao aceitar as condições/imposições do outro, Marabá abriu mão de sua condição de cidadã, logo, desse seu lugar de sujeito. Dessa forma, Marabá estava muito mais próxima de se tornar cidadã enquanto seu interlocutor a rejeitava, rebatendo seus argumentos, do que quando ela mesma se vê como Marabá, no sentido dado por esse mesmo interlocutor, ou seja, enquanto era vista como mistura, como mestiça.

O que se nota, nesse caso, é que o discurso do interlocutor de Marabá acaba por fazêla mudar a forma de ver a si mesma. Depreende-se, então, nos propósitos de Brandão (2004), que o entrelaçamento dos diversos discursos que permeiam o espaço sócio-histórico-ideológico em que se inserem os sujeitos desempenha importante papel na constituição identitária. 


\section{CONSIDERAÇÕES FINAIS}

Com essa análise do poema romântico Marabá, pode-se notar a importância da alteridade para a constituição da identidade. Ainda que a índia miscigenada tenha envidado esforços para se reafirmar enquanto sujeito autêntico, com suas características particulares e, naquele momento, inovadoras em meio a sua tribo, sua identidade é determinada pelo confronto de visões ideológicas traduzidas nos discursos em conflito. Marabá não consegue ser o que ela enxerga em si mesma, mas o como é vista pelo outro.

O processo de construção identitária consolida-se na coletividade. Ainda que parta de um sujeito individual, sua legitimação e autoaceitação depende, sobremaneira, da reação intersubjetiva. Negada pela totalidade de sua comunidade, torna-se impossível para Marabá a autoafirmação. Identidade não é, portanto, um fenômeno solitário, precisa ser vista pelo outro, nem que seja por um subgrupo minoritário.

É também interessante notar a potência dos discursos na construção/estabelecimento do sujeito social. No poema, a ideologia por detrás dos discursos anti-Marabá, ou seja, antimistura, pautada na ilusão de uma raça pura, como se existisse povo no mundo que não derivasse de algum tipo de miscigenação, sobrepõe-se à realidade. Marabá é uma realidade negada e vencida. Sua invisibilização promovida pelos discursos impera inclusive sobre a própria vítima, que, ao final do poema, cede-lhe lugar. Portanto, no corpus analisado, o discurso exerce papel essencial para a constituição identitária do sujeito em sociedade.

\section{REFERÊNCIAS BIBLIOGRÁFICAS}

AUGÉ, Marc. Por uma antropologia da mobilidade. Trad. Bruno César Cavalcante; Raquel Rocha Almeida Barros; Maceió: EDUFAL: UNESP, 2010.

BRANDÃO, Maria Helena Nagamine. Introdução à Análise do Discurso. 2. ed. rev. Campinas: Unicamp, 2004.

BOSI, Alfredo. História Concisa da Literatura Brasileira. 47. ed. - São Paulo: Cultrix, 2006.

DIAS, Gonçalves. Marabá. Disponível em: http://www.jornaldepoesia.jor.br/gdias02.html. Acesso em: 05 out 2018.

FOUCAULT, Michel. A hermenêutica do sujeito. Trad. Márcio Alves da Fonseca, Salma Tannus Muchail. 2. ed. São Paulo: Martins Fontes, 2006.

HALL, Stuart. A identidade cultural na pós-modernidade. 11. ed. Rio de Janeiro: DP\&A, 2006. Jangada | nr. 16, jun/dez, 2020 | ISSN 2317-4722 
MANZINI-COVRE, Maria de Lourdes. O que é cidadania. Col. Primeiros Passos. São Paulo: Brasiliense, 2007.

TOURAINE, Alain. A busca de si: diálogo sobre o sujeito. Tradução de Caio Meira. Rio de Janeiro: Bertrand Brasil, 2004. 